\title{
Analisis Quality of Service (QoS) Pada Jaringan Hotspot SMA Negeri XYZ
}

\author{
Sumbogo Wisnu Pamungkas ${ }^{1}$, Kusrini ${ }^{2}$, Eko Pramono. ${ }^{3}$ \\ ${ }^{1,2,3}$ Magister Teknik Informatika Universitas AMIKOM Yogyakarta \\ E-mail: ${ }^{1}$ Sumbogo8122@ @students.amikom.ac.id, ${ }^{2}$ Kusrini@amikom.ac.id, \\ 3eko.p@amikom.ac.id
}

\begin{abstract}
Abstrak
Jaringan yang baik harus memperhatikan kualitas layanan yang akan diberikan kepada pengguna. Ketika membangun sebuah jaringan harus memperhitungkan Quality of Service (QoS). Quality of Service (QoS) merupakan metode pengukuran seberapa baik suatu layanan jaringan. parameter-parameter Quality of Service (QoS) yaitu troughput,delay,jitter, dan packet loss menurut standart THIPON.Pada SMA Negeri XYZ untuk mendukung proses pembelajaran menyediakan sarana dan prasarana tambahan, salah satunya ialah tersedianya jaringan internet. Layanan internet pada sekolah ini mengguakan Internet Service Provider (ISP) dari PT Telkom Indonesia dan bandwidth yang di sewa sebesar 40Mbps. SMA Negeri XYZ menyediakan jaringan hotspot sebagai sarana untuk guru atau siswa menggunakan jaringan internet. Oleh karena itu sangat diperlukan pengukuran untuk mengetahui seberapa baik kualitas layanan yang telah diberikan. Hasil dari pengukuran Quality of Service (QoS) pada jaringan hotspot SMA Negeri XYZ dapat diketahui bahwa troughputnya sebesar "3,94 bps", delay sebesar "0 ms", Jitter sebesar "0 ms", dan packet loss sebesar " 11,46 \%". Maka dapat di simpulkan bahwa kualitas jaringan hotspot pada SMA Negeri XYZ menurut standart THIPON masuk dalam kategori "Sedang".
\end{abstract}

Kata Kunci : Quality of Service, bandwidth, troughput,delay,jitter, packet loss.

\begin{abstract}
A good network must be designed to deliver good quality of service for customers. Quality of service must be put into account before we build a network. Quality of service is a method to determine how the network delivers a service. According to THIPON standard, Quality of service has some parameters, those are troughput,delay,jitter, and packet loss. In order to support learning process, high school of ABC provides additional infrastructures, one of them is internet network. Network at this school uses internet services provided by PT Telkom Indonesia and the bandwidth is $40 \mathrm{Mbps}$. High school of $A B C$ provides a hotspot as a media for teachers and students so they can access the internet. Therefore, thorough measurement is necessary to measure how well the service is delivered. The result of quality of service measurement of hotspot network in high school of $A B C$ indicates that the troughput is "3,94 bps", the delay is " 0 ms", the Jitter is " $0 \mathrm{~ms}$ ", and packet loss is " $11,46 \%$ ". We can put a conclusion that hotspot network in high school of ABC is categorized as "medium" according to the standard of THIPON
\end{abstract}

Keywords - Quality of Service, bandwidth, troughput,delay,jitter, packet loss.

\section{Pendahuluan}

Ketika membangun sebuah jaringan jangan lupa juga memperhitungkan Quality of Service (QoS). Jika Quality of Service (QoS) yang diberikan kepada pelanggan tidak baik, maka pengguna akan tidak merasa nyaman menggunakan jaringan tersebut. Quality of Service (QoS) JURNAL SISTEM INFORMASI DAN TEKNOLOGI INFORMASI

Vol. 7, No. 2, Okrober 2018 
merupakan metode pengukuran seberapa baik suatu layanan jaringan [1]. Beberapa parameter yang Quality of Service (QoS) yaitu troughput,delay,jitter,dan packet loss menurut standart THIPON

Pada SMA Negeri XYZ memiliki saran dan prasarana tambahan, salah satunya ialah tersedianya jaringan internet. SMA Negeri XYZ menggunakan ISP (Internet Service Provider) dari PT Telkom Indonesia untuk layanan internet dan bandwidth yang disewa pada sekolah ini sebesar 40 Mbps. SMA Negeri XYZ menyediakan jaringan hotspot sebagai sarana untuk guru atau siswa menggunakan jaringan internet. Oleh karena itu sangat diperlukan pengukuran untuk mengetahui seberapa baik kualitas layanan atau Quality of Service $(\mathrm{QoS})$ yang telah diberikan.

Permasalah yang ada ialah mengetahui seberapa baik kualitas layanan yang telah diberikan, maka dalam penelitian ini bertujuan meneliti bagaimana Quality of Service (QoS) pada jaringan hotspot SMA XYZ. Sebagai rekomendasi untuk SMA Negeri XYZ dalam meningkatkan kualitas jaringan hotspot.

Penelitian sebelumnya pernah dilakukan oleh (Imam, 2017) melakukan penelitian tentang manajemen bandwidth menggunakan simple queue pada mikrotik di SMK PGRI 1 kota Kediri. Hasil dari penelitian ini setelah dilakukan manajemen bandwidth sudah dikonfigurasikan setiap client mendapatakan kecepatan upload 256kbps dan untuk download sebesar 512kbps [2].Penelitian lain dilakukan oleh (Nurul, 2018) melakukan penelitian tentang analisa performansi QoS layanan video streaming pada jaringan MPLS-DiffServ dan MPLS-IntServ. Hasil dari menunjukkan bahwa parameter delay dalam Quality of Service (QoS) pada jaringan MPLS-DiffServ dan MPLS-IntServ telah memenuhi standart ITUT G.114 dalam kategori "Baik" [3].Penelitian lain dilakukan oleh (Umar, 2015) melakukan penelitian tentang" analisis Rogue dhcp packets menggunakan wireshark network protocol analyzer". Hasil dari penelian ini didapatkan informasi parameter-parameter yang terkandung di dalam Rogue DHCP Packets yang difungsikan untuk membangun sistem keamanan jaringan $D H C P$ [3].

Perbedaan penelitian yang dilakukan dengan penelitian (Imam, 2017) dalam penelitian ini tidak ada pengukuran Quality of Service (QoS) hanya sekedar mengetahui troughput yang di terima oleh client saja. Perbedaan dengan penelitian (Nurul, 2018) Pada penelitian ini Quality of Service (QoS) hanya di ukur di parameter delay saja. Perbedaan dengan penelitian (Umar, 2015) dalam penelitian ini wireshark digunakan mengetahui paket paket yang lewat untuk mencegah adanya Rogue DHCP Server. Sedangkan pada penelitian yang akan dilakukan akan mengetahui Quality of Service (QoS) dan parameter yang digunakan troughput, delay, jitter, dan packetloss.

\section{Metode Penelitian}

\subsection{Analisi Quality of Service (QoS)}

Quality of Services (QoS) merupakan mekanisme pada jaringan yang menentukan bahwa aplikasi-aplikasi atau layanan dapat beroperasi sesuai dengan standart kualitas layanan yang telah diterapkan. Parameter-parameter Quality of Services (QoS) seperti troughput, latency, jitter,dan packetloss [1].

Ada Standart Quality of Services (QoS) salah satunya adalah THIPON (Telecomunications and Internet Protocol Harmonization Over Network) TR.101329.V2.1.1.1999-06 yang dikeluarkan oleh ETSI (European Telecommunications Standards Institude) nilai Quality of Service (QoS) dapat dilihat pada tabel 1[5].

Tabel 1. Kategori Standard Nilai QoS

\begin{tabular}{|c|c|c|}
\hline Nilai Indek & Presentase (\%) & Kategori \\
\hline $3,8-4$ & $95-100 \%$ & Sangat Bagus \\
\hline $3-3,79$ & $75-94,75 \%$ & Bagus \\
\hline $2-2,99$ & $50-74,75 \%$ & Sedang \\
\hline
\end{tabular}


$1-1,99$

$25-49,75 \%$

Jelek

\subsection{Parameter Quality of Service (QoS)}

Ada beberapa parameter dari Quality of Service $(Q o S)$, diantaranya :

a. Throughput

Throughput merupakan kecepatan traransver data. Throughput adalah jumlah total kedatangan paket yang sukses diamati pada tujuan selama interval waktu tertentu dibagi oleh durasi interval waktu tersebut [5]. Adapun kategori Throughput menurut TIPHON adalah sebagai berikut.

Tabel 2. Standarisasi Throughput

\begin{tabular}{|c|c|c|}
\hline $\begin{array}{c}\text { Kategori } \\
\text { Throughput }\end{array}$ & $\begin{array}{c}\text { Throughput } \\
\text { (bps) }\end{array}$ & Indeks \\
\hline Sangat Bagus & 100 & 4 \\
\hline Bagus & 75 & 3 \\
\hline Sedang & 50 & 2 \\
\hline Jelek & $>25$ & 1 \\
\hline
\end{tabular}

Persamaan Peritungan Throughput :

b. Delay

$$
\text { Throughput }=\frac{\text { Jumlah Data yang Dikirm }}{\text { Waktu Pengiriman Data }}
$$

Delay adalah waktu yang dibutuhkan sebuah data untuk menempuh jarak dari asal ke tujuan. Delay dapat dipengaruhi oleh jarak media fisik, kongesti atau waktu lama proses yang lama [5]. Adapun kategori Delay menurut TIPHON adalah sebagai berikut.

Tabel 3. Standarisasi Delay

\begin{tabular}{|c|c|c|}
\hline Kategori Latency & Besar Delay & Indeks \\
\hline Sangat Bagus & $<150 \mathrm{~ms}$ & 4 \\
\hline Bagus & $150 \mathrm{~s} / \mathrm{d} 300 \mathrm{~ms}$ & 3 \\
\hline Sedang & $300 \mathrm{~s} / \mathrm{d} 450 \mathrm{~ms}$ & 2 \\
\hline Jelek & $>450 \mathrm{~ms}$ & 1 \\
\hline
\end{tabular}


c. Jitter

Persamaan Peritungan Delay:

$$
\operatorname{Delay}(\mathrm{s})=\frac{\text { Total Delay }}{\text { Total Paket Yang Diterima }}
$$

Jitter adalah variasi delay, yang disebabkan oleh variasi-variasi panjang antrian dalam waktu mengolah data. Delay antrian pada router dan switch dapat menyebabkan jitter [5]. Adapun kategori Jitter menurut TIPHON adalah sebagai berikut.

Tabel 4. Standarisasi Jitter

\begin{tabular}{|c|c|c|}
\hline Kategori Latency & Besar Jitter & Indeks \\
\hline Sangat Bagus & $0 \mathrm{~ms}$ & 4 \\
\hline Bagus & $75 \mathrm{~ms}$ & 3 \\
\hline Sedang & $125 \mathrm{~ms}$ & 2 \\
\hline Jelek & $225 \mathrm{~ms}$ & 1 \\
\hline
\end{tabular}

Persamaan Peritungan Jitter :

$$
\text { Jitter }=\frac{\text { Total Variasi Delay }}{\text { Total Paket Yang Diterima }}
$$

Total variasi Delay $=$ Delay $-($ rata-rata delay $)$

d. Packetloss

Packet loss adalah banyaknya paket yang gagal mencapai tempat tujuan paket tersebut dikirim [5]. Adapun kategori Packetloss menurut TIPHON adalah sebagai berikut.

Tabel 5. Standarisasi packetloss

\begin{tabular}{|c|c|c|}
\hline Kategori Packet loss & Packet loss & Indeks \\
\hline Sangat bagus & $0 \%$ & 4 \\
\hline Bagus & $3 \%$ & 3 \\
\hline Sedang & $15 \%$ & 2 \\
\hline Jelek & $25 \%$ & 1 \\
\hline
\end{tabular}

Persamaan Peritungan Packetloss:

$$
\text { Packet loss }=\frac{(\text { Paket Data Dikirm }- \text { Paket Data Diterima })}{\text { Paket data yang dikirim }} \times 100 \%
$$

\subsection{Metode Pengumpulan Data}

Terdapat dua jenis data yang diperoleh dalam metode pengumpulan data ini, yaitu data primer dan data sekunder. 
1. Data Primer

a. Observasi merupakan merupakan mengumpulkan data data atau informasi mengenai kebutuhan sistem. Dalam penelitian ini, peneliti melakukan pengamatan secara langsung pada objek penelitian SMA Negeri XYZ.

b. Wawancara merupakan percakapan, proses tanya jawab antar dua orang atau lebih yang berhadapan secara fisik. Wawancara dilakukan kepada admin jaringan pada objek penelitian SMA Negeri XYZ.

2. Data Sekunder

Data sekunder adalah data yang diperoleh dari referensi teori atau data-data dokumentasi yang relevan dengan penelitian yang dilakukan. Referensi diperoleh dari berbagai sumber antara lain buku, jurnal, website, dan laporan tesis.

\subsection{Metode Analisis Data}

Metode analisis data yang digunakan adalah analisis data kuantitatif. Metode kuantitatif merupakan metode penelitian yang digunakan meneliti populasi atau sample tertentu dan dilakukan secara random. Sample data diambil langsung pada objek penelitian SMA Negeri XYZ.

\subsection{Alur Penelitian}

Alur penelitian yang dilakukan dalam penelitian ini adalah sebagai berikut :

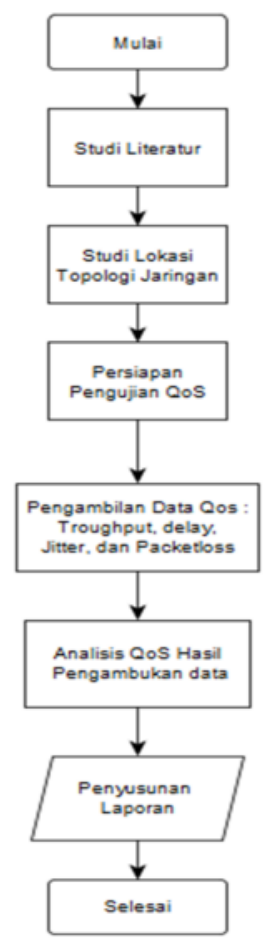

Gambar 5. Alur Penelitian

Alur penelitian ini dimulai dari pengumpulan studi literatur yang sesuai dengan tema yang peneliti akan lakukan. Kemudian peneliti melakukan studi langsung ada objek penelitian tentang bagaimana kondisi topologi jaingan yang sedang berjalan. Selanjutnya peneliti melakukan persiapan pengujian Quality of Service (QoS). Setelah itu dilakukan pengambilan data Quality of Service (QoS) pada objek berupa troughput, delay, jitter, dan packetloss. Setelah 
dilakukan pegambilan data kemudian dilakukan analisis dan kemudian dilakukan penyusunan laporan.

\subsection{Topologi Jaringan Penelitian}

Topologi yang diterapkan saat ini dan masih sedang berjalan pada penelitian ini adalah sebagai berikut.

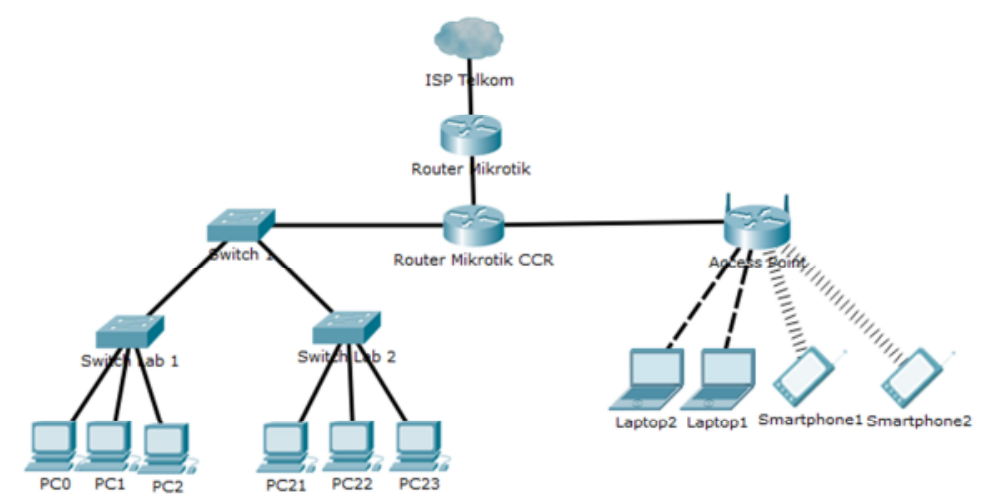

Gambar 4, Topologi Pada SMA Negeri XYZ

SMA Negeri XYZ menggunakan ISP dari PT Telkom Indonesia. Bandwidth yang disewa sebesar 40Mbps. Pada router mikrotik CCR pada Eth0/1 digunakan untuk terhubung dengan router mikrotik utama dengan IP address 192.168.1.2. Eth0/2 digunakan untuk lab dengan IP address 192.168.3.0/24. Eth0/4 digunakan untuk hotspot dengan IP address 192.168.4.0/24 Pada penelitian ini hanya berfokus pada hotspot saja karena pada objek penelitian ini kebanyakan pengguna menggunakan hotspot.

\section{Hasil dan Pembahasan}

\subsection{Analisis Data}

Pada penelitian ini, dilakukan beberapa skenario pengambilan data dan dilakukan 4 kali pengambilan data dan akan di bandingkan dengan standar jaringan yang ada yaitu dengan standar THIPON. Dalam penelitia ini data yang diambil berupa sample tertentu dan dilakukan secara random. Data yang diambil adalah troughput, delay, jitter, dan packetloss. Pengujian dilakukan dengan mengcapture paket sebanyak 4 kali selama jam belajar mengajar sedang berlangsung. Data pertama diambil pada pukul 08.00 WIB sampai dengan pukul 10.00 WIB. Data ke dua diambil pada pukul 10.00 WIB sampai dengan pukul 12.00 WIB. Data ke tiga diambil pada pukul 13.00 WIB sampai dengan pukul 14.00 WIB. Data ke empat diambil pada pukul 14.00 WIB sampai dengan pukul 16.00 WIB.Software wireshark digunakan pada sisi router. Berikut ini adalah tampilan awal wireshark. Data diambil langsung pada objek penelitian yaitu SMA Negeri XYZ. 


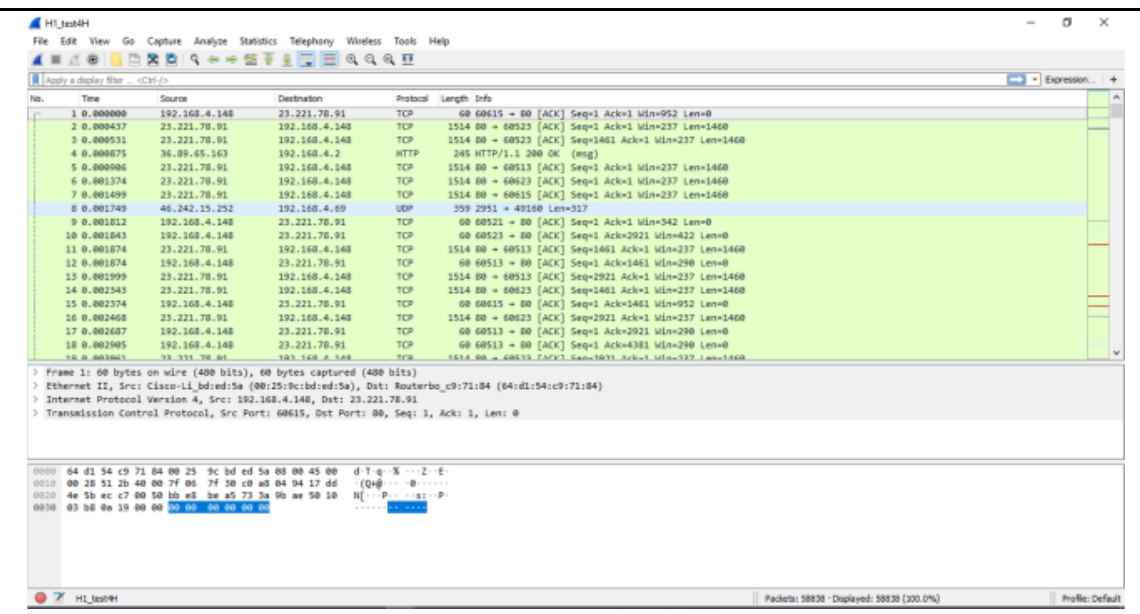

Gambar 5. Tampilan Awal Wireshark

Wireshark merupakan salah satu aplikasi open source yang digunkan oleh admin jaringan untuk menganalisa protocol jaringan. Alasan kenapa admin banyak menggunakan tool ini selain dapat melihat data dengan detail dan wireshark bebas untuk digunakan oleh siapa saja [7].

\subsection{Hasil Pengukuran Data}

Berdasarkan hasil pengambilan data QoS (Quality of Service) diperoleh hasil pengukuran sebagai berikut :

1) Troughput

Hasil pengukuran troughput pada jam belajar mengajar sedang berlangsung hasilnya ditampilkan pada tabel 6 dan nilai troughput sesuai dengan versi TIPHON sebagai standarisasi. Data diambil antara jam 08.00 WIB - 10.00 WIB, jam 10.00 WIB 12.00 WIB, jam 12.00 WIB - 14.00 WIB, dan jam 14.00 WIB - 16.00 WIB.

Tabel 6. Pengukuran Troughput

\begin{tabular}{|c|c|c|c|c|}
\hline \multirow{2}{*}{ No } & Jam & Troughput & \multicolumn{2}{|c|}{ Keterangan } \\
\cline { 4 - 5 } & & bps $)$ & Indeks & Kategori \\
\hline 1 & 08.00 WIB $-10.00 \mathrm{WIB}$ & 4,01 & 1 & Jelek \\
\hline 2 & $10.00 \mathrm{WIB}-12.00 \mathrm{WIB}$ & 3,84 & 1 & Jelek \\
\hline 3 & $12.00 \mathrm{WIB}-14.00 \mathrm{WIB}$ & 3,94 & 1 & Jelek \\
\hline 4 & $14.00 \mathrm{WIB}-16.00 \mathrm{WIB}$ & 3,97 & 1 & Jelek \\
\hline & Rata Rata Troughput & 3,94 & 1 & Jelek \\
\hline
\end{tabular}

Berdasarkan tabel 6 hasil pengukuran troughput menurut standart THIPON dalam kategori "jelek" dengan rata-rata troughput 3,94 bps. 
2) Delay

Hasil pengukuran delay pada jam belajar mengajar sedang berlangsung hasilnya ditampilkan pada tabel 7 dan nilai delay sesuai dengan versi TIPHON sebagai standarisasi. Data diambil antara jam 08.00 WIB - 10.00 WIB, jam 10.00 WIB 12.00 WIB, jam 12.00 WIB - 14.00 WIB, dan jam 14.00 WIB - 16.00 WIB.

Tabel 7. Pengukuran delay

\begin{tabular}{|c|c|c|c|c|}
\hline \multirow{2}{*}{ No } & \multirow{2}{*}{ Jam } & \multirow{2}{*}{$\begin{array}{c}\text { Delay } \\
(\mathrm{ms})\end{array}$} & \multicolumn{2}{|c|}{ Keterangan } \\
\cline { 4 - 5 } & & & Indeks & Kategori \\
\hline 1 & 08.00 WIB $-10.00 \mathrm{WIB}$ & 0 & 4 & Sangat bagus \\
\hline 2 & $10.00 \mathrm{WIB}-12.00 \mathrm{WIB}$ & 0 & 4 & Sangat bagus \\
\hline 3 & $12.00 \mathrm{WIB}-14.00 \mathrm{WIB}$ & 0 & 4 & Sangat bagus \\
\hline 4 & $14.00 \mathrm{WIB}-16.00 \mathrm{WIB}$ & 0 & 4 & Sangat bagus \\
\hline & Rata Rata Delay & 0 & 4 & Sangat bagus \\
\hline
\end{tabular}

Berdasarkan tabel 7 hasil pengukuran delay menurut standart THIPON dalam kategori "sangat bagus" dengan rata-rata delay $0 \mathrm{~ms}$.

3) Jitter

Hasil pengukuran jitter pada jam belajar mengajar sedang berlangsung hasilnya ditampilkan pada tabel 8 dan nilai jitter sesuai dengan versi TIPHON sebagai standarisasi. Data diambil antara jam 08.00 WIB - 10.00 WIB, jam 10.00 WIB 12.00 WIB, jam 12.00 WIB - 14.00 WIB, dan jam 14.00 WIB - 16.00 WIB.

Tabel 8. Pengukuran Jitter

\begin{tabular}{|c|c|c|c|c|}
\hline & & \multirow{2}{*}{$\begin{array}{c}* \\
\text { No }\end{array}$} & Jam & \multicolumn{2}{|c|}{ Keterangan } \\
\cline { 4 - 5 } & & & Indeks & Kategori \\
\hline 1 & $08.00 \mathrm{WIB}-10.00 \mathrm{WIB}$ & 0 & 4 & Sangat bagus \\
\hline 2 & $10.00 \mathrm{WIB}-12.00 \mathrm{WIB}$ & 0 & 4 & Sangat bagus \\
\hline 3 & $12.00 \mathrm{WIB}-14.00 \mathrm{WIB}$ & 0 & 4 & Sangat bagus \\
\hline 4 & $14.00 \mathrm{WIB}-16.00 \mathrm{WIB}$ & 0 & 4 & Sangat bagus \\
\hline
\end{tabular}




\begin{tabular}{|c|c|c|c|c|}
\hline \multirow{2}{*}{ No } & & \multirow{2}{*}{$\begin{array}{c}|c| \\
\text { Jitter } \\
(\mathrm{ms})\end{array}$} & \multicolumn{2}{|c|}{ Keterangan } \\
\cline { 3 - 5 } & & Indeks & Kategori \\
\hline \multirow{2}{*}{ Rata Rata Jitter } & 0 & 4 & Sangat bagus \\
\hline
\end{tabular}

Berdasarkan tabel 8 hasil pengukuran jitter menurut standart THIPON dalam kategori "sangat bagus" dengan rata-rata jitter $0 \mathrm{~ms}$.

4) Packetloss

Hasil pengukuran packetloss pada jam belajar mengajar sedang berlangsung hasilnya ditampilkan pada tabel 9 dan nilai packetloss sesuai dengan versi TIPHON sebagai standarisasi. Data diambil antara jam 08.00 WIB - 10.00 WIB, jam 10.00 WIB $12.00 \mathrm{WIB}$, jam $12.00 \mathrm{WIB}-14.00 \mathrm{WIB}$, dan jam $14.00 \mathrm{WIB}-16.00 \mathrm{WIB}$.

Tabel 9. Pengukuran Packetloss

\begin{tabular}{|c|c|c|c|c|}
\hline \multirow{2}{*}{ No } & \multirow{2}{*}{ Jam } & \multirow{2}{*}{$\begin{array}{c}\text { Packetloss } \\
(\%)\end{array}$} & \multicolumn{2}{|c|}{ Keterangan } \\
\hline & & & Indeks & Kategori \\
\hline 1 & $08.00 \mathrm{WIB}-10.00 \mathrm{WIB}$ & 14,27 & 2 & Sedang \\
\hline 2 & $10.00 \mathrm{WIB}-12.00 \mathrm{WIB}$ & 12,31 & 2 & Sedang \\
\hline 3 & $12.00 \mathrm{WIB}-14.00 \mathrm{WIB}$ & 10,05 & 2 & Sedang \\
\hline 4 & $14.00 \mathrm{WIB}-16.00 \mathrm{WIB}$ & 9,23 & 2 & Sedang \\
\hline & Rata Rata Packetloss & 11,46 & 2 & Sedang \\
\hline
\end{tabular}

Berdasarkan tabel 9 hasil pengukuran packetloss menurut standart THIPON dalam kategori "sedang" dengan rata-rata packetloss $11,46 \%$.

Dari hasil pengukuran Quality of Service (QoS) di dapat hasil troughput 3,94 bps dengan kategori "jelek" dan nilai indek 1. Delay $0 \mathrm{~ms}$ dengan kategori "Sangat Memuaskan" dan nilai indek 4. Jitter 0 ms dengan kategori "Sangat Memuaskan" dan nilai indek 4. Packetloss 11,46 \% dengan kategori "Sedang" dan nilai indek 2. Seperti pada tabel 10. 
Tabel 10. Tabel Indek Quality of Service

\begin{tabular}{|c|c|c|c|}
\hline \multirow{2}{*}{ No } & Quality of Service (QoS) & \multicolumn{2}{|c|}{ Keterangan } \\
\cline { 3 - 4 } & & Indeks & Kategori \\
\hline 1 & Troughput & 1 & Jelek \\
\hline 2 & Delay & 4 & Sangat Bagus \\
\hline 3 & Jitter & 4 & Sangat Bagus \\
\hline 4 & Packetloss & 2 & Sedang \\
\hline & Rata Rata Indek & 2,75 & Sedang \\
\hline
\end{tabular}

Berdasarkan standarisasi THIPON untuk kategori nilai "Sangat Bagus" jika nilai QoS 3,8 - 4, "Bagus" jika nilai QoS 3 - 3,79, "Sedang" jika nilai QoS 2 - 2,99 dan "Jelek" jika nilai QoS 1 - 1,99. Dari tabel 10 indek Quality of Service menurut standart THIPON didapat hasil 2,75 dengan kategori "Sedang".

\section{Kesimpulan}

Bedasarkan hasil analisis Quality of Service (QoS) di SMA Negeri XYZ, maka didapat kesimpulan sebagai berikut :

1. Pengukuran Quality of Service (QoS) pada SMA Negeri XYZ dilakukan dengan tool wireshark dan beberapa parameter QoS yang digunakan yaitu troughput, delay, jitter, dan packetloss.

2. Pengukuran Quality of Service (QoS) di dapat hasil troughput 3,94 bps dengan kategori "Jelek", delay 0 ms dengan kategori "Sangat Memuaskan", jitter $0 \mathrm{~ms}$ dengan kategori "Sangat Memuaskan", dan packetloss 11,46 \% dengan kategori "Sedang".

3. Hasil pengukuran Quality of Service (QoS) pada SMA Negeri XYZ menurut standar THIPON didapat hasil 2,75 dengan kategori "Sedang".

\section{Saran}

Agar alokasi bandwidth yang diberikan kepada salah satu client tidak berlebihan dan menyebabkan client lain terganggu. Maka perlu dilakukannya menejemen bandwidth untuk dapat menjaga kestabilan koneksi internet masing-masing client.

\section{Daftar Pustaka}

[1] Irawati, Indrarini Dyah, dkk. Jaringan Komputer dan Data Lanjut. Yogyakarta: Deepuplish, 2015.

[2] Imam Prawito, Agus, "Manajemen Bandwidth Menggunakan Simple Queue Pada 
Jaringan Internet Sistem Kuota Di IAIN Palopo”. Jurnal Ilmiah Ilmu-Ilmu Teknik. Vol. 1, No.1, 2017.

[3] Fadhilah, Nurul., dkk, "Analisa Performansi Qos Layanan Video Streaming Pada Jaringan Mpls-Diffserv Dan Mpls-Intserv". Elektro Dan Telekomunikasi Terapan. Vol 5 No 1, 2018.

[4] Kadafi, Muamar, “Analisis Rogue DHCP Packets Menggunakan Wireshark Network Protocol Analyzer". Citec Journal, Vol. 2, No. 2, 2015.

[5] ETSI TR.101329.V2.1.1. 1999-06. Telecomunications and Internet Protocol Harmonization Over Network); General aspects of Quality of Service (QoS). https://www.etsi.org/deliver/etsi_tr/101300_101399/101329/02.01.01_60/tr_101329v02010 1p.pdf Diakses pada tanggal 15 Juni 2019.

[6] Madcoms, Sistem jaringan komputer untuk pemula. Yogyakarta: andi offset, 2010.

[7] A. Kurniawan, Network Forensics: Panduan Analisis dan Investigasi Paket Data Jaringan menggunakan Wireshark, Yogyakarta: Andi, 2012.

[8] Syahrul Anwar, Dede, "Sistem Informasi Geografis Pemetaan Jaringan Pelanggan Indihome Berbasis Web Di PT.Telkom Cabang Singaparna", Voice Of Informatics (VOI), Vol. 6, No. 2, 2017.

[9] Syafrizal, Melwin. Pengantar Jaringan Komputer. Yogyakarta: Andi. 2005.

[10] Towidjojo, Rendra. Mikrotik Kung Fu Kitab 3. Jakarta: Jasakom. 2016.

[11] Towidjojo, Rendra. Mikrotik Kung Fu Kitab 1. Jakarta: Jasakom. 2019. 